\title{
Tecnologia assistiva e suas relações com a qualidade de vida de pessoas com deficiência
}

\section{Assistive technology and its relationship to the quality of life of people with disabilities}

\author{
Renata Ferreira dos Santos 1 , Priscila Yukari Sewo Sampaio ${ }^{1}$, Ricardo Aurélio \\ Carvalho Sampaio ${ }^{1}$, Gustavo Luis Gutierrez ${ }^{1}$, Marco Antonio Bettine de Almeida ${ }^{2}$
}

http://dx.doi.org/10.11606/issn.2238-6149.v28i1p54-62

\begin{abstract}
Ferreira RS, Sampaio PYS, Sampaio RAC, Gutierrez GL, Almeida MAB. Tecnologia assistiva e suas relações com a qualidade de vida de pessoas com deficiência. Rev Ter Ocup Univ São Paulo. 2017 jan.-abr.;28(1):54-62.
\end{abstract}

RESUMO: Introdução: A tecnologia assistiva apresenta produtos, recursos, métodos, estratégias, práticas e serviços que promovem a funcionalidade de pessoas com deficiência, visando sua autonomia, independência, qualidade de vida e inclusão social. Seu desenvolvimento e disponibilização podem ser considerados uma tentativa de neutralizar as barreiras causadas pela deficiência. Objetivo: Compreender e apontar as relações existentes entre tecnologia assistiva e qualidade de vida de pessoas com deficiência. Método: Utilizou-se a história de vida tópica. Foram entrevistadas três pessoas com deficiência física/motora, três com deficiência visual, e três com deficiência auditiva. Identificou-se individualmente a relação entre tecnologia assistiva e qualidade de vida, e os traços em comum nas respostas considerando o "grupo" da deficiência. Resultado: As aplicações da tecnologia assistiva englobam atividades da vida diária, atividades instrumentais de vida diária, educação, trabalho e lazer, que implicam diferentes relações com a qualidade de vida. Conclusão: A tecnologia assistiva está relacionada à qualidade de vida de pessoas com deficiência ao facilitar e possibilitar a realização das atividades, promovendo autonomia e independência, gerando efeitos positivos individuais e sociais.

DESCRITORES: Pessoas com deficiência; Equipamentos de autoajuda; Qualidade de vida.
Ferreira RS, Sampaio PYS, Sampaio RAC, Gutierrez GL, Almeida MAB. Assistive technology and its relationship to the quality of life of people with disabilities. Rev Ter Ocup Univ São Paulo. 2017 Jan.-Apr.;28(1):54-62.

ABSTRACT: Introduction: Assistive technology offers products, resources, methods, strategies, practices and services that promote functionality, autonomy, independence, quality of life and social inclusion for people with disabilities. Its development and deployment can be considered an attempt to neutralize the barriers caused by disability. Objective: To understand and point out the relationship between assistive technology and quality of life of people with disabilities. Method: We used the topical life story. Three subjects with physical/motor disability, three with visual impairment and three with hearing impairment were interviewed. The relationship between assistive technology and quality of life was investigated individually for each subject, in addition to the common patterns in responses considering the "group" of disability. Result: Applications of assistive technologie include activities of daily living, instrumental activities of daily living, education, work and leisure, playing different relationships with quality of life. Conclusion: Assistive technologie is related to the quality of life of people with disabilities facilitating and making possible the activities performances, promoting autonomy and independence, creating individual and social positive effects.

KEYWORDS: Disabled persons; Self-help devices; Quality of life.

Este trabalho é parte integrante da dissertação de mestrado de: Ferreira RS. Novas tecnologias e seus impactos na qualidade de vida de pessoas com deficiência. Campinas, Universidade Estadual de Campinas. Campinas; 2015.

Esta pesquisa foi financiada pelo Conselho Nacional de Desenvolvimento Científico e Tecnológico (CNPq).

1. Universidade Estadual de Campinas. E-mails: renata_guittar@hotmail.com, pryukari@hotmail.com, sampaiorac@hotmail.com, gutierrez@fef.unicamp.br

2. Universidade de São Paulo. E-mail: marcobettine@usp.br

Endereço para correspondência: Renata Ferreira dos Santos. Rua Quintino Bocaiúva, 384 - Centro Alto. Ribeirão Pires, SP, Brasil. CEP: 09424-030. 
Ferreira RS, et al. Tecnologia assistiva e suas relações com a qualidade de vida. Rev Ter Ocup Univ São Paulo. 2017 jan./abr.;28(1):54-62.

\section{INTRODUÇÃO}

$\mathrm{T}$ ecnologia Assistiva (TA) é uma área de conhecimento interdisciplinar, que apresenta produtos, recursos, métodos, estratégias, práticas e serviços que promovem a funcionalidade de pessoas com deficiência, incapacidades ou mobilidade reduzida, visando sua autonomia, independência, qualidade de vida (QV) e inclusão social ${ }^{1}$.

A TA pode ser aplicada em atividades que exigem desempenho humano, como tarefas básicas de autocuidado, até as profissionais, sociais, culturais, esportivas e de lazer ${ }^{2}$. Galvão Filho e Damasceno ${ }^{3}$ afirmam que desenvolver e disponibilizar TA são uma das tentativas de neutralizar as barreiras causadas pela deficiência, que possibilitaria a inserção do indivíduo em ambientes ricos para a aprendizagem, oriundos da cultura. Rocha e Miranda ${ }^{4}$ ressaltam que a sociedade precisa se adaptar às necessidades das pessoas com deficiência, dividindo seus espaços com igualdade, respeito e aceitação às diferenças. A TA pode auxiliar isso, por proporcionar ou ampliar as habilidades funcionais de pessoas com deficiência, promovendo vida independente e inclusão.

$\mathrm{O}$ acesso aos mesmos bens que as demais pessoas têm é um direito que não pode ser tirado das pessoas com deficiência, mesmo que o modo de organizar as atividades seja repensado e modificado ${ }^{5}$.

A acessibilidade promove a inclusão, a equiparação de oportunidades e o exercício da cidadania para todos. Ações que garantam a acessibilidade para pessoas com restrição de mobilidade aos sistemas de transportes, equipamentos urbanos, e a circulação em áreas públicas suscitam o respeito de seus direitos fundamentais como indivíduos (p.46) .

Já existe tecnologia para se comunicar por telefone com uma pessoa surda, e para uma pessoa cega ou com limitação física severa se comunicar via Internet. Pessoas com deficiência visual ou auditiva podem participar de conferências com vídeos e palestras faladas. O braile, a libras, a audiodescrição, a legenda oculta, o sistema DAISY para livros, e outras adequações da informação estão disponíveis, mas utilizadas raramente (por emissoras de televisão, editoras de livros, companhias telefônicas e conferências), por permanecerem desconhecidas pelas pessoas em geral $^{6}$.

A QV é uma área relativamente recente de pesquisa, que está consolidando suas fronteiras e conceitos, neste sentido, as definições por ela recebidas são comuns, mas geralmente discordantes ${ }^{7}$. A Organização Mundial da Saúde (OMS) define QV como

A percepção do indivíduo de sua posição na vida, no contexto da cultura e do sistema de valores em que vive e em relação aos seus objetivos, expectativas, padrões e preocupações (p.32, 33) .

Esta definição integra duas concepções para entender a QV:

Objetividade das condições materiais (a posição do indivíduo na vida e as relações sociais); e subjetividade (o conhecimento sobre as condições físicas, emocionais e sociais relacionadas aos aspectos temporais, culturais e sociais como são percebidas pelo sujeito) (p.33) .

A análise da QV sob a objetividade das condições materiais compreende elementos quantificáveis e concretos, passíveis de serem modificados pelos atos humanos. Visa abordar as necessidades essenciais para a sobrevivência, tais como alimentação, moradia, acesso à saúde, emprego, saneamento básico, educação, transporte. Sob o aspecto subjetivo enfatiza as mudanças históricas, sociais, culturais, referentes às condições de bens materiais e de serviços, que são interpretadas individualmente. Não caracteriza os níveis de vida somente dos dados objetivos, pois os conecta as condições subjetivas e emocionais, expectativas, realizações, percepção sobre a vida, e assuntos como prazer, felicidade, angústia e tristeza. Não há como excluir o impacto destas variáveis, pois elas variam de acordo com a individualidade ${ }^{7}$.

Artigos originais e de revisão tem verificado empírica e conceitualmente o uso da TA para diferentes propósitos e populações ${ }^{9-12}$. Analisar as TAs utilizadas por pessoas adultas com diferentes deficiências, e sua relação com a QV, contribui para a valorização das mesmas, ao destacar os seus efeitos, que ultrapassam o âmbito funcional, envolvendo aspectos éticos, estéticos, afetivos, subjetivos, entre outros ${ }^{12}$. Dessa forma, este artigo busca compreender e apontar as relações existentes entre TA e QV de pessoas com deficiência física/motora, visual e auditiva.

\section{PROCEDIMENTOS METODOLÓGICOS}

A pesquisa foi financiada pelo Conselho Nacional de Desenvolvimento Científico e Tecnológico (CNPq), e aprovada pelo Comitê de Ética em Pesquisa da Faculdade de Ciências Médicas da Universidade Estadual de Campinas - FCM/UNICAMP (parecer 794060). 
Ferreira RS, et al. Tecnologia assistiva e suas relações com a qualidade de vida. Rev Ter Ocup Univ São Paulo. 2017 jan./abr.;28(1):54-62.

Utilizou-se como referencial metodológico a história de vida tópica considerando a análise de uma fase ou setor da vida pessoal ${ }^{13}$. Este método retrata as experiências e definições fornecidas por pessoas, grupos ou organizações. Para isso, é feita uma entrevista em profundidade, na qual geralmente há liberação de pensamento crítico, e a expressão de um olhar cuidadoso sobre a própria vivência ou fato. Através do relato, é possível refletir a dimensão coletiva a partir da visão individual ${ }^{14}$.

Os sujeitos foram recrutados por conveniência. Os critérios de inclusão foram: (a) condição de deficiência física/motora, visual ou auditiva; (b) maior de 18 anos de idade e (c) usar TA. Os critérios de exclusão foram: não ter deficiência, ter outros tipos de deficiências ou incapacidades, menores de idade, e não usar TA.

Foram feitas 9 entrevistas: 3 com pessoas com deficiência física/motora, 3 com pessoas com deficiência visual, e 3 com pessoas com deficiência auditiva, em locais de sua preferência. Priorizou-se a pesquisa em profundidade e não o alto número de entrevistas, dentro de um prazo de 6 meses (período estipulado para o estudo), mantendo um equilíbrio no número de participantes de acordo com a deficiência analisada.

Os participantes assinaram o Termo de Consentimento Livre e Esclarecido (TCLE), autorizando o uso dos dados para fins acadêmicos. Para as pessoas com deficiência visual, o TCLE foi lido em voz alta na presença de uma testemunha.

A entrevista biográfica baseou-se em 3 questões: (1) história de vida, destacando a condição de deficiência; (2) tipos de TA utilizadas e desejadas; (3) uso de TA e vida social.

Quando necessário, o entrevistador adicionou perguntas, porém nenhuma sobre QV, para avaliar se os voluntários relacionariam $\mathrm{TA}$ à $\mathrm{QV}$ espontaneamente, o que ocorreu. As entrevistas foram gravadas e transcritas ${ }^{15}$, visando o conteúdo integral dos dados. As pessoas com deficiência auditiva foram entrevistadas com o auxílio de um intérprete de libras.

Os dados foram categorizados conforme a deficiência dos sujeitos. Primeiro, identificou-se individualmente a relação entre o uso de TA e QV. Em seguida, os traços em comum nas respostas considerando o "grupo" da deficiência, para elucidarmos as diferenças e necessidades existentes, que se manifestam de acordo com a condição. As informações foram dispostas em quadros e descrições adicionais foram abordadas textualmente.

\section{RESULTADOS}

O Quadro 1 relata as características gerais dos entrevistados. Observa-se que o entrevistado mais jovem tinha 26 anos, enquanto o mais velho tinha 45 anos. Sete homens e duas mulheres participaram do estudo. Adicionalmente, o nível de escolaridade predominante foi superior e pós-graduado.

As aplicações da TA relatadas pelos entrevistados compreenderam atividades da vida diária (AVDs), atividades instrumentais de vida diária (AIVDs), educação, trabalho e lazer. Os Quadros 2, 3 e 4 apresentam a descrição da TA, sua relação com a QV, e a TA desejada pelos entrevistados, de acordo com o tipo de deficiência.

O Entrevistado 1 (E1) apresentava tetraplegia, sem sensibilidade nem movimento do nível da axila para baixo. Nos membros superiores, possuía bastante déficit de força, não conseguia movimentar os dedos das mãos e tinha restrição nos movimentos do punho. O Entrevistado 2 (E2) também apresentava tetraplegia, apesar de ter recuperado alguns movimentos de membros superiores, e a sensibilidade no corpo todo. Já o entrevistado 3 (E3) apresentava paraplegia. As aplicações da TA relatadas pelos entrevistados com deficiência física/motora compreenderam desde atividades da vida diária (AVDs), atividades instrumentais de vida diária (AIVDs), educação, trabalho e lazer (Quadro 2).

Quadro 1 - Caracterização dos sujeitos da pesquisa

\begin{tabular}{|llllll|}
\hline Sujeito & Idade & Sexo & Deficiência & Escolaridade & Profissão \\
\hline Entrevistado 1 & 37 anos & Masculino & Física/motora - Adquirida & Pós-graduação & Professor, Atleta \\
\hline Entrevistado 2 & 26 anos & Masculino & Física/motora - Adquirida & Superior & Atleta \\
\hline Entrevistado 3 & 33 anos & Masculino & Física/motora - Adquirida & Técnico & Ferramenteiro \\
\hline Entrevistado 4 & 27 anos & Masculino & Visual - Adquirida & Pós-graduação & Sociólogo \\
\hline Entrevistado 5 & 42 anos & Masculino & Visual - Adquirida & Pós-graduação & Físico, Professor \\
\hline Entrevistado 6 & 28 anos & Feminino & Visual - Congênita & Técnico & Técnica Administrativa \\
\hline Entrevistado 7 & 29 anos & Masculino & Auditivo - Congênito & Superior & Administrador \\
\hline Entrevistado 8 & 29 anos & Masculino & Auditivo - Adquirido & Superior & Tecnólogo de Redes \\
\hline Entrevistado 9 & 45 anos & Feminino & Auditivo - Adquirido & Técnico & Técnica Administrativa \\
\hline
\end{tabular}


Ferreira RS, et al. Tecnologia assistiva e suas relações com a qualidade de vida. Rev Ter Ocup Univ São Paulo. 2017 jan./abr.;28(1):54-62.

Quadro 2 - TA utilizada, relações com a QV e TA desejada pelos entrevistados com deficiência física/motora

\begin{tabular}{|c|c|c|c|c|}
\hline Sujeito & Tipo da deficiência & Principal TA utilizada & Relações com a QV & Principal TA desejada \\
\hline Entrevistado 1 & $\begin{array}{l}\text { Física/motora } \\
\text { Tetraplegia }\end{array}$ & $\begin{array}{l}\text { Adaptador p/ escova de } \\
\text { dentes e barbeador; cadeira } \\
\text { para banho } \\
\text { Adaptação para teclado e } \\
\text { mouse TrackBall } \\
\text { Cadeira de rodas } \\
\text { Adaptador para marcador e } \\
\text { giz } \\
\text { Adaptador para raquete de } \\
\text { tênis de mesa } \\
\text { Veículo adaptado }\end{array}$ & $\begin{array}{l}\text { Desempenhar tarefas de } \\
\text { higiene pessoal } \\
\text { Usar o computador } \\
\text { Locomover-se } \\
\text { Escrever } \\
\text { Praticar esporte } \\
\text { Dirigir }\end{array}$ & $\begin{array}{l}\text { Adaptador para pequenos } \\
\text { botões de controle remoto, } \\
\text { telefone, outros } \\
\text { Cadeira de rodas motorizada } \\
\text { Esqueleto externo }\end{array}$ \\
\hline Entrevistado 2 & $\begin{array}{l}\text { Física/motora } \\
\text { Tetraplegia }\end{array}$ & $\begin{array}{l}\text { Adaptador para aparelho de } \\
\text { barbear } \\
\text { Tábua de transferência } \\
\text { Cadeira de rodas } \\
\text { Adaptador para gaita e } \\
\text { baquetas de bateria } \\
\text { Veículo adaptado }\end{array}$ & $\begin{array}{l}\text { Desempenhar as tarefas de } \\
\text { higiene pessoal } \\
\text { Deslocar-se de um lugar para } \\
\text { outro } \\
\text { Locomover-se; obter melhora } \\
\text { na postura, respiração, } \\
\text { segurança e equilíbrio do } \\
\text { tronco } \\
\text { Tocar instrumentos } \\
\text { Dirigir }\end{array}$ & Nenhuma \\
\hline Entrevistado 3 & $\begin{array}{l}\text { Física/motora } \\
\text { Paraplegia }\end{array}$ & $\begin{array}{l}\text { Órtese para ortostatismo e } \\
\text { deambulação em ambiente } \\
\text { doméstico } \\
\text { Aerobike } \\
\text { Cadeira de rodas } \\
\text { Veículo adaptado }\end{array}$ & $\begin{array}{l}\text { Praticar atividade física com } \\
\text { os membros inferiores } \\
\text { Locomover-se } \\
\text { Dirigir }\end{array}$ & Nenhuma \\
\hline
\end{tabular}

Com relação às AVDs, o E1 usava um adaptador para se alimentar. Com o tempo, o instrumento foi abandonado pela falta de praticidade. Com relação à higiene pessoal, ele não conseguia desempenhá-la sem o uso de uma adaptação. Para escovar os dentes ou se barbear, por exemplo, fazia uso de um adaptador que ele próprio confeccionou com EVA. Para o banho, contava com o auxílio de uma cadeira de banho, entre outras estratégias.

No momento da pesquisa, o E2, conseguia segurar a escova de dentes e o garfo sem necessidade de adaptadores, mas continuava usando um adaptador em seu aparelho de barbear (informação verbal).

No âmbito da mobilidade funcional, o E2 utilizava uma tábua para fazer transferência, mas sentia muita falta de conseguir usar a força do próprio tríceps por não conhecer nenhuma outra tecnologia que pudesse lhe ajudar neste sentido (informação verbal). Também, relatou que a utilização da cadeira de rodas o ajuda em questões de postura, respiração, segurança e equilíbrio de tronco (informação verbal). O E3 conta com o auxílio de uma órtese que lhe possibilita ficar de pé e andar dentro de sua casa, mas não para fazer marcha na rua, pois esta objetiva apenas o ortostatismo (informação verbal). $\mathrm{O}$ E1 compartilhou o desejo de ter uma cadeira de rodas motorizada, pois talvez, uma cadeira motorizada poderia ajudá-lo a sair de sua casa para fazer algo na região, sem que precisasse ir de carro. A cadeira motorizada poderia ser um facilitador para subir ladeiras e rampas sozinho. Também, citou a vontade de ter um esqueleto externo, o que lhe possibilitaria ficar de pé, e andar.

Já com relação às AIVDs, no gerenciamento de comunicação, o E1 utilizava um adaptador para escrita, porém descontinuou o uso por considerá-lo trabalhoso, preferindo utilizar outras formas de segurar o lápis. O E1 tinha um adaptador de teclado de computador, e devido às suas dificuldades de movimentar o mouse convencional 
Ferreira RS, et al. Tecnologia assistiva e suas relações com a qualidade de vida. Rev Ter Ocup Univ São Paulo. 2017 jan./abr.;28(1):54-62.

(como posicionar corretamente o cursor na tela e o tempo necessário para a execução desta atividade), optou por usar o mouse TrackBall (informação verbal). A peculiaridade do mouse TrackBall é que o usuário deve manipular uma esfera geralmente localizada em sua parte superior para mover o cursor na tela, diferentemente do mouse convencional que requer mover o dispositivo todo em uma superfície plana ou mouse pad. Devido à sua dificuldade em pinçar, o E1 também gostaria que objetos pequenos tivessem adaptações, como controles remotos, telefones, objetos que contém botões, ou mesmo pen drives. Já o E2, por não apresentar nenhum movimento de dedos, e consequentemente ter dificuldade para apertar botões, preferia utilizar o mouse pad, e também o sistema touch screen para celular (informação verbal).

Quanto às atividades de lazer, o E2 costumava tocar instrumentos musicais antes de adquirir a deficiência, e por isso, a equipe de reabilitação the proporcionou uma adaptação para gaita e baquetas de bateria. Importante, o entrevistado destacou o papel do centro de reabilitação para o restabelecimento de sua autonomia e independência (informação verbal). O E1 reportou o uso de um adaptador para conseguir segurar o taco de bilhar, porém, como não conseguia se posicionar muito bem à mesa de bilhar, o adaptador pouco funcionou, sendo então abandonado. Ele utilizava outro adaptador que lhe permitia jogar tênis de mesa, que já tem o formato para ser encaixado no dedo indicador (informação verbal). O E3 relatou o uso de uma aerobike, ao realizar o movimento com as mãos/braços os pés/pernas também se moviam.

Em relação às pessoas com deficiência visual, os entrevistados apresentavam cegueira total adquirida, visão subnormal adquirida (gerada pela doença de Stargardt), e cegueira total congênita (Quadro 3).

Quadro 3 - TA utilizada, relações com a QV e TA desejada pelos entrevistados com deficiência visual

\begin{tabular}{|c|c|c|c|c|}
\hline Sujeito & Tipo da deficiência & Principal TA utilizada & Relações com a QV & Principal TA desejada \\
\hline Entrevistado 4 & $\begin{array}{l}\text { Visual } \\
\text { Cegueira total } \\
\text { adquirida }\end{array}$ & $\begin{array}{l}\text { Adaptadores para materiais } \\
\text { didáticos } \\
\text { Braile } \\
\text { Bengala } \\
\text { Leitor de tela no computador }\end{array}$ & $\begin{array}{l}\text { Auxílio na aprendizagem } \\
\text { Ler } \\
\text { Locomover-se } \\
\text { Usar o computador }\end{array}$ & Cão-guia \\
\hline Entrevistado 5 & $\begin{array}{l}\text { Visual } \\
\text { Visão subnormal } \\
\text { adquirida (Stargardt) }\end{array}$ & $\begin{array}{l}\text { Relógio falante } \\
\text { Leitor de tela no computador } \\
\text { Braile }\end{array}$ & $\begin{array}{l}\text { Ter informações sobre o } \\
\text { horário } \\
\text { Usar o computador } \\
\text { Ler }\end{array}$ & $\begin{array}{l}\text { Rádio digital } \\
\text { Acessibilidade ambiental } \\
\text { nas universidades públicas } \\
\text { como rampas, pisos táteis, } \\
\text { elevadores adaptados }\end{array}$ \\
\hline Entrevistado 6 & $\begin{array}{l}\text { Visual } \\
\text { Cegueira total } \\
\text { congênita }\end{array}$ & $\begin{array}{l}\text { Adaptadores para materiais } \\
\text { didáticos } \\
\text { Leitor de tela no computador } \\
\text { Braile }\end{array}$ & $\begin{array}{l}\text { Auxílio na aprendizagem } \\
\text { Usar o computador } \\
\text { Ler }\end{array}$ & $\begin{array}{l}\text { Impressora em braile } \\
\text { Maior disponibilidade de } \\
\text { filmes com audiodescrição } \\
\text { nos cinemas }\end{array}$ \\
\hline
\end{tabular}

Os entrevistados citaram diferentes estratégias e recursos que foram empregados para as atividades de educação e gerenciamento de comunicação durante o seu período de alfabetização. O Entrevistado 4 (E4) afirmou que quando tinha baixa visão, ter acesso a um caderno de pauta larga, e caneta esferográfica foi fundamental. Destacou que a adaptação de materiais didáticos, dependendo da abordagem, pode ser considerada como TA. Por exemplo, na infância, no uso de textura para esquemas corporais, maquetes de matemática, cubos e prismas, aos quais teve acesso (informação verbal). A Entrevistada 6 (E6) relatou que foi alfabetizada por sua própria mãe, através de estímulo táctil que consistia em barbantes colados em papel, no formato das letras. Aprendeu o braile após algum tempo, quando se mudou do sítio para a cidade. Ingressou na escola regular aos 13 anos de idade, na $4^{\mathrm{a}}$ série, e prosseguindo no supletivo. Algumas vezes, suas provas eram aplicadas em braile, e outras vezes, oralmente pelos professores (informação verbal).

O Entrevistado 5 (E5) relatou utilizar o braile esporadicamente, mas o tem trocado pela praticidade do computador. Ele fazia uso de um relógio falante que descreveu como muito útil. Além de um serviço da sua operadora de telefonia móvel para despertador. Para o E5, mesmo as 
Ferreira RS, et al. Tecnologia assistiva e suas relações com a qualidade de vida. Rev Ter Ocup Univ São Paulo. 2017 jan./abr.;28(1):54-62.

páginas da Internet, não são acessíveis porque são construídas para pessoas normovisuais, enquanto que a pessoa com deficiência visual depende de programas específicos para ter a mesma oportunidade. Ele não tinha acesso ao próprio e-mail pelo sistema da faculdade em que trabalhava, por que o dispositivo era completamente inacessível.

A E6 citou que muitas coisas chegam ao mercado, mas demoram certo tempo para ficarem acessíveis às pessoas com deficiência visual, um exemplo disso são as redes sociais digitais (Whatsapp, Youtube, e Facebook, por exemplo) (informação verbal). A E6 comentou que antes de ter acesso à Internet, sentia-se excluída das conversas de seus amigos.

Com relação ao uso da TA para a mobilidade na comunidade, o E4 destacou o uso da bengala como muito marcante na perda da visão, por que passa a ser um estigma, ao mesmo tempo em que é um recurso que possibilita a independência e a liberdade. Em um primeiro momento, as pessoas com deficiência visual que são vistas com a bengala, são rotuladas. Diante disso, o seu uso é uma forma de assumir socialmente a cegueira, uma vez que se a pessoa com deficiência visual é vista parada, sem óculos escuro e sem a bengala, a sua deficiência pode passar despercebida (informação verbal).

O E4 comentou que se tivesse outra rotina de vida, e morasse em uma cidade maior, gostaria de ter acesso a um cão-guia, o que ainda é muito restrito no país (informação verbal). A E6 sentia falta de uma impressora braile, e relatou dificuldades em seu curso de inglês, por não ter acesso ao material de estudo. Também, gostaria de ter um carro, e que filmes em audiodescrição fossem mais disponibilizados nos cinemas (informação oral), como uma opção de atividade de lazer e/ou de participação social. O E5 gostaria de ter um rádio digital com sintonia a diversas rádios, com fácil manuseio. Também gostaria de adaptações nas universidades públicas, pois estas ainda carecem de acessibilidade, como rampas, pisos táteis, elevadores adequados.

As pessoas com deficiência auditiva que participaram da pesquisa eram hipoacústicas, e apenas o Entrevistado 7 (E7) apresentava deficiência auditiva congênita (Quadro 4). Em resumo, pontuam o uso do aparelho auditivo, e da libras, mesmo sendo oralizadas.

O Entrevistado 7 (E7) não utilizava nenhum outro tipo de tecnologia além do aparelho auditivo. Já o Entrevistado 8 (E8) explicou que apesar de não gostar de usar o aparelho auditivo, se não o usa, sente uma certa revolta, por não saber o que as pessoas estão falando (informação verbal). A Entrevistada 9 (E9) ressaltou que gostaria que alguns locais lhe fornecessem seus contatos via e-mail, ao invés de números telefônicos (informação verbal).

Quadro 4 - TA utilizada, relações com a QV e TA desejada pelos entrevistados com deficiência auditiva

\begin{tabular}{|c|c|c|c|c|}
\hline Sujeito & Tipo da deficiência & Principal TA utilizada & Relações com a QV & Principal TA desejada \\
\hline Entrevistado 7 & $\begin{array}{l}\text { Auditiva } \\
\text { Congênita }\end{array}$ & $\begin{array}{l}\text { Aparelho auditivo } \\
\text { Libras }\end{array}$ & $\begin{array}{l}\text { Ouvir } \\
\text { Comunicar-se }\end{array}$ & Nenhuma \\
\hline Entrevistado 8 & $\begin{array}{l}\text { Auditiva } \\
\text { Hipoacústica }\end{array}$ & $\begin{array}{l}\text { Aparelho auditivo } \\
\text { Libras }\end{array}$ & $\begin{array}{l}\text { Ouvir } \\
\text { Comunicar-se }\end{array}$ & Nenhuma \\
\hline Entrevistado 9 & $\begin{array}{l}\text { Auditiva } \\
\text { Hipoacústica }\end{array}$ & $\begin{array}{l}\text { Aparelho auditivo } \\
\text { Libras }\end{array}$ & $\begin{array}{l}\text { Ouvir } \\
\text { Comunicar-se }\end{array}$ & $\begin{array}{l}\text { Contatos via e-mail dos } \\
\text { estabelecimentos }\end{array}$ \\
\hline
\end{tabular}

\section{DISCUSSÃO}

As pessoas com deficiência física/motora afirmaram abandonar a TA quando é difícil o manuseio ou transporte da mesma. A TA depende da adaptação do usuário, por isso, deve ser de fácil utilização. Seu sucesso não depende exclusivamente da disposição da TA em repor a ausência do membro ou de sua funcionalidade, mas também da adesão da pessoa com deficiência ${ }^{16}$.

Os adultos com deficiência visual ${ }^{15}$, confirmaram a relevância dos softwares, citando os sistemas DOSVOX, JAWS, Virtual Vision, TALKS, e Victor Reader (leitores de tela) e o sistema touch screen para celular. A relação sujeito- objeto gera a experiência, capaz de conectar o indivíduo com o mundo exterior. Um exemplo disso é quando uma pessoa com deficiência visual deslumbra uma paisagem fornecida pelo JAWS, experimentando sensações compenetradas na imagem produzida pelo software ${ }^{16}$.

As Novas Tecnologias de Informação e Comunicação são o veículo da visibilidade no meio dos outros seres visíveis. Ele vê além do visível ocular. Seu corpo é um ser táctil, pode ser tocado e tocante, como quando o software JAWS através da audição, oferece à pessoa cega uma leitura de mundo (p.86) ${ }^{17}$. 
Para Santos e Pequeno ${ }^{17}$ a acessibilidade ao conhecimento digital maximiza o tempo e as potencialidades do incluído digital, pois a informática é um apoio capaz de aprimorar as condições de vida das pessoas. Na Internet, a pessoa com deficiência encontra informações sobre saúde, educação, trabalho, entre outras, além de se sociabilizar. Para os autores, a inclusão digital é fundamental para as pessoas com deficiência, e seu acesso não deve limitarse à rede de informações, mas sim, eliminar as barreiras arquitetônicas, inserir equipamentos e programas apropriados, e disponibilizar conteúdos em diversas formas.

Para Fialho e Silva ${ }^{18}$, a tecnologia é relevante para a pessoa com deficiência visual (por facilitar o acesso à informação), e para as pessoas com as quais se relaciona. Seus efeitos ultrapassam o individual e atingem o coletivo. Nisto, a tecnologia deve ser divulgada e acessível a todas as pessoas com deficiência, inclusive financeiramente. A falta de informações ou de condições financeiras pode fazer com que seus familiares não as aceitem, como citado nas entrevistas.

Maciel $^{19}$ explica que a não aceitação é maior junto aqueles que possuem poucos recursos econômicos, o que minimiza as suas oportunidades de um atendimento qualificado. O potencial e habilidades das pessoas com deficiência são pouco valorizados nas suas comunidades de origem, por certamente possuírem pouco esclarecimento a respeito das deficiências. A escassez de conhecimento leva a sociedade a considerar a deficiência como uma doença crônica, um peso ou um problema.

Para os sujeitos da pesquisa, muitas pessoas com deficiência têm preconceito de si mesmas, quando, por exemplo, não usam a bengala, por acharem estranho ou por medo da opinião alheia. A bengala pode ser um símbolo estigmatizante, para a própria pessoa com deficiência que a usa ${ }^{16}$.

Os sujeitos com deficiência auditiva utilizam apenas o aparelho auditivo. Mesmo não gostando do aparelho auditivo, sua não utilização pode implicar revolta. A não compreensão da fala das pessoas pode levar as pessoas com deficiência a se sentirem excluídas, ou a sofrerem preconceito, o que afirma a influência da TA nas relações sociais.

A pessoa com deficiência, ao romper suas limitações na realização de tarefas cotidianas, estabelece uma compensação moral própria, com o intuito de remediar a desigualdade física, para salvar sua dignidade e facilitar sua inclusão nas relações sociais, mesmo que pareça que este dever se debruça demasiadamente na sua própria vontade, desprezando as condições externas que moderam tal processo $^{16}$.
Para Martins e Barsaglini $^{16}$, qualquer posicionamento adotado pela pessoa com deficiência não faz com que sua autoimagem deixe de ser corrompida pela comparação, no sentido de que, publicamente, apresentando-se fora do padrão, ela estará sempre em evidência. A diferença visível ou invisível pode influenciar a dinâmica das interações sociais, pois, ocultar a diferença, mesmo que isto seja uma defesa contra a exposição, ainda assim preserva o medo da descoberta, que é equivalente à dúvida dos acontecimentos que as condições crônicas apresentam. Para Goffman ${ }^{20}$, muitas atitudes dos normais são guiadas pelo desconhecimento, e não contém má intenção. Tais pessoas precisam ser ajudadas, e suas observações indelicadas de menosprezo e desdém, não correspondidas.

A força universal dos símbolos de estigmas da deficiência se manifesta por serem generalizantes, incorporados e introjetados mesmo em culturas separadas no tempo e no espaço, perpetuando a experiência de gerações, sendo sempre alusiva à depreciação físico-moral dos seus portadores, e que pode ser visível a todos (p.119) ${ }^{16}$.

Há uma ambiguidade em relação às tecnologias, pois elas não eliminam o estigma através das modificações realizadas pelos recursos técnicos, acontecimento que frequentemente é desconsiderado durante a criação de tais dispositivos. Em algumas situações, a visibilidade de próteses, cadeira de rodas, entre outros, torna-se o princípio do estigma publicamente, devido à exacerbação da diferença. O uso da TA, principalmente a de difícil disfarce, pode estar associado ao que Goffman ${ }^{20}$ denominou de símbolos estigmatizantes que, como as marcas corporais, transmitem informações sociais que despertam a atenção sobre a diferença, e reduzem, consequentemente, a valorização da pessoa ${ }^{16}$.

Segundo a $\mathrm{ABNT}^{21}$, acessibilidade é a possibilidade e condição de alcance para utilização, com segurança e autonomia, de edificações, espaço, mobiliário e equipamentos urbanos. As barreiras arquitetônicas (obstáculos construídos no meio urbano ou nos edifícios) que impedem ou dificultam o acesso a ambientes internos ou externos em edificações de uso público ou privado, são importantes questões a serem discutidas ${ }^{22}$.

A sociedade só pode ser acessível com alguns quesitos básicos, que são aliados à tecnologia:

a) acessibilidade arquitetônica: sem barreiras ambientais físicas nas casas, edifícios, espaços ou equipamentos 
Ferreira RS, et al. Tecnologia assistiva e suas relações com a qualidade de vida. Rev Ter Ocup Univ São Paulo. 2017 jan./abr.;28(1):54-62.

urbanos e nos meios de transportes individuais ou coletivos; b) acessibilidade comunicacional: sem barreiras na comunicação interpessoal, escrita e virtual; c) acessibilidade metodológica: sem barreiras nos métodos e técnicas de estudo, trabalho, ação comunitária e educação dos filhos; d) acessibilidade instrumental: sem barreiras nos instrumentos, utensílios e ferramentas de estudo, trabalho, lazer ou recreação; e) acessibilidade programática: sem barreiras invisíveis embutidas em políticas públicas e normas ou regulamentos; e f) acessibilidade atitudinal: sem preconceitos, estigmas, estereótipos e discriminações (p.18) ${ }^{23}$.

Esta discussão aponta que a TA amplia as oportunidades e manutenção dos papéis ocupacionais, o que gera mudança na vida das pessoas com deficiência, possivelmente impactando diretamente a sua QV. A condição individual deve ser refletida (na tetraplegia, por exemplo, existe uma infinidade de comprometimentos diferentes), pois cada pessoa tem necessidades e preferências específicas, que os levam a utilizar uma determinada TA. A mensuração desta singularidade pode ser considerada uma limitação deste estudo.

\section{REFERÊNCIAS}

1. Brasil. Secretaria Especial dos Direitos Humanos. Subsecretaria Nacional de Promoção dos Direitos da Pessoa com Deficiência. Comitê de Ajudas Técnicas. Tecnologia Assistiva. Brasília: CORDE; 2009. Disponível em: http:// www.pessoacomdeficiencia.gov.br/app/sites/default/files/ publicacoes/livro-tecnologia-assistiva.pdf.

2. Brasileiro ASP. Tecnologia "Assistiva" no contexto da atividade motora adaptada [Monografia]. Campinas: Universidade Estadual de Campinas; 2003. Disponível em: file://C:/Users/ Administrador/Downloads/BrasileiroAldaSoniaPeres_TCE.pdf.

3. Galvão Filho TA, Damasceno LL. Tecnología asistida en entorno informático: recursos para la autonomía e inclusión socioinformática de la persona con discapacidad. In: Programa InfoEsp: premio Reina Sofia 2007 de Rehabilitación y de Integración. Madrid: Ministerio de Educación, Política Social y Deporte/ Real Patronato sobre Discapacidad; 2008. Disponível em: http://www.infoesp.net/ premio.pdf.

4. Rocha TB, Miranda TG. A inclusão de alunos com deficiência no ensino superior: uma análise de seu acesso e permanência. In: Díaz F, Bordas M, Galvão N, Miranda T, organizadores.

\section{CONCLUSÕES}

A TA pode ser relacionada à $\mathrm{QV}$ de pessoas com deficiência na medida em que é facilitadora de atividades, e principalmente, possibilita a participação, promovendo autonomia e independência. Isso gera efeitos positivos individuais e sociais, fazendo com que pessoas com deficiência passem de seres incapazes a indivíduos aptos a desempenharem as mesmas atividades que as pessoas sem deficiência.

Quanto aos tipos de deficiência abordados e suas relações com a $\mathrm{QV}$, notou-se que para as pessoas com deficiência física, a utilização da TA está ligada à independência e autonomia para a realização das AVDs; às questões de saúde voltadas à postura e respiração; e à locomoção e acessibilidade. Para as pessoas com deficiência visual, o uso está relacionado à locomoção e ao acesso à informação. As pessoas com deficiência auditiva apresentaram um perfil menos restritivo em comparação às demais deficiências, o que não diminuiu a importância da TA, essencial para auxiliar em sua audição. Em todos os casos, a TA está sujeita à aprovação do usuário, que precisa adaptar-se a ela, para utilizá-la.

Educação inclusiva, deficiência e contexto social: questões contemporâneas. Salvador: EDUFBA; 2009. p.27-37. Disponível em: http://books.scielo.org/id/rp6gk/03.

5. Alcoba SAC. Estranhos no ninho: a inclusão de alunos com deficiência na Unicamp [tese]. Campinas: Universidade Estadual de Campinas; 2008.

6. Vital FMP, Queiroz MA. Acessibilidade. In: Resende APC, Vital FMP, coordenadores. A convenção sobre os direitos das pessoas com deficiência - versão comentada. Brasília: Secretaria Especial dos Direitos Humanos; 2008. Disponível em: https://www.governoeletronico.gov.br/documentos-earquivos/A\%20Convencao $\% 20$ sobre $\% 20$ os $\% 20$ Direitos $\% 20$ das $\% 20$ Pessoas $\% 20$ com $\% 20$ Deficiencia\%20Comentada.pdf.

7. Almeida MAB, Gutierrez GL, Marques RR. Qualidade de vida: definição, conceitos e interfaces com outras áreas de pesquisa. São Paulo: Edições EACH; 2012 [citado 15 mar. 2013]. Disponível em: http://each.uspnet.usp.br/edicoeseach/qualidade_vida.pdf.

8. Vilarta R, Gonçalves A. Qualidade de vida - concepções básicas voltadas à saúde. In: Gonçalves A, Vilarta R, 
Ferreira RS, et al. Tecnologia assistiva e suas relações com a qualidade de vida. Rev Ter Ocup Univ São Paulo. 2017 jan./abr.;28(1):54-62.

organizadores. Qualidade de vida e atividade física: explorando teorias e práticas. Barueri: Manole; 2004.

9. Alves ACJ, Matsukura TS. O uso de recursos de tecnologia assistiva por crianças com deficiência física na escola regular: a percepção dos professores. Cad Ter Ocup UFSCar (São Carlos). 2012;20(3):381-92. doi: 10.4322/cto.2012.038.

10. Albuquerque KF, Moreira MAP, Costa SMG, Costa CC, Patrício ACFA. Tecnologias assistivas para a pessoa idosa: revisão integrativa da literatura. Rev Pesq Cuid Fund. 2011;3(n. esp.):184-8. doi: 10.9789/2175-5361.2011.

11. Parreira SLS, Santos VR, Rosseto LP, Diniz DS, Oliveira ASB. Equipe interdisciplinar para utilização de tecnologias assistivas de comunicação alternativa e aumentativa. Fronteiras J Soc Technol Environ Sci. 2015;3(1):334-42. doi: 10.21664/2238-8869.2015v4i1.p334-342.

12. Rocha EF, Castiglioni MC. Reflexões sobre recursos tecnológicos: ajudas técnicas, tecnologia assistiva, tecnologia de assistência e tecnologia de apoio. Rev Ter Ocup Univ São Paulo. 2005;16(3):97-104. doi: 10.11606/issn.2238-6149.v16i3p97-104.

13. Minayo MCS. O desafio do conhecimento: pesquisa qualitativa em saúde. Rio de Janeiro: Abrasco; 1996.

14. Cruz Neto O. O trabalho de campo como descoberta e criação. In: Minayo MCS, organizador. Pesquisa social: teoria, método e criatividade. 18a ed. Petrópolis: Vozes; 2001.

15. Ferreira RS. Novas tecnologias e seus impactos na qualidade de vida de pessoas com deficiência [dissertação]. Campinas: Universidade Estadual de Campinas; 2015. Disponível em: http://www.bibliotecadigital.unicamp.br/ document $/$ ?code $=000945963$.

16. Martins JA, Barsaglini RA. Aspectos da identidade na experiência da deficiência física: um olhar socioantropológico.
Interface (Botucatu). 2011;15(36):109-22. doi: 10.1590/180757622013.0280 .

17. Santos LP, Pequeno R. Novas tecnologias e pessoas com deficiência: a informática na construção da sociedade inclusiva? In: Sousa RP, Moita FMGSC, Carvalho ABG, organizadores. Tecnologias digitais na educação. Campina Grande: EDUEPB; 2011. p.75-103. Disponível em: http:// books.scielo.org/id/6pdyn/pdf/sousa-9788578791247-04.pdf.

18. Fialho J, Silva DO. Informação e conhecimento acessíveis aos deficientes visuais nas bibliotecas universitárias. Perspect Cienc Inform. 2012;17(1):153-68. doi: 10.1590/S141399362011000100001.

19. Maciel MRC. Portadores de deficiência: a questão da inclusão social. São Paulo Perspec. 2000;13(2):51-6. doi: 10.1590/ S0102-88392000000200008.

20. Goffman E. Estigma: notas sobre a manipulação da identidade deteriorada. 4a ed. Rio de Janeiro: Ed. Guanabara; 1988. Disponível em: https://edisciplinas.usp.br/pluginfile.php/92113/ mod_resource/content/1/Goffman\%3B\%20Estigma.pdf.

21. Associação Brasileira de Normas Técnicas (ABNT). NBR9050. Acessibilidade a edificações, mobiliário, espaços e equipamentos urbanos. Rio de Janeiro; 2004.

22. Emmel MLG, Castro CB. Barreiras arquitetônicas no campus universitário: o caso da UFSCar. In: Marquezini MC, Almeida MA, Busto RM, organizadores. Educação física, atividades lúdicas e acessibilidade de pessoas com necessidades especiais. Londrina: UEL; 2003. (Coleção Perspectivas Multidisciplinares em Educação Especial).

23. Melo AM. Acessibilidade e design universal. In: Pupo DT, Melo AM, Ferrés SP, organizadores. Acessibilidade: discurso e prática no cotidiano das bibliotecas. Campinas: Unicamp; 2006. 